ARTICLE

\title{
The 2019/20 Australian wildfires generated a persistent smoke-charged vortex rising up to $35 \mathrm{~km}$ altitude
}

Sergey Khaykin (1D ${ }^{1 凶}$, Bernard Legras ${ }^{2}$, Silvia Bucci ${ }^{2}$, Pasquale Sellitto $\mathbb{B}^{3}{ }^{3}$, Lars Isaksen ${ }^{4}$, Florent Tencé (i) ${ }^{1}$, Slimane Bekki ${ }^{1}$, Adam Bourassa ${ }^{5}$, Landon Rieger ${ }^{5}$, Daniel Zawada ${ }^{5}$, Julien Jumelet ${ }^{1} \&$ Sophie Godin-Beekmann ${ }^{1}$

The Australian bushfires around the turn of the year 2020 generated an unprecedented perturbation of stratospheric composition, dynamical circulation and radiative balance. Here we show from satellite observations that the resulting planetary-scale blocking of solar radiation by the smoke is larger than any previously documented wildfires and of the same order as the radiative forcing produced by moderate volcanic eruptions. A striking effect of the solar heating of an intense smoke patch was the generation of a self-maintained anticyclonic vortex measuring $1000 \mathrm{~km}$ in diameter and featuring its own ozone hole. The highly stable vortex persisted in the stratosphere for over 13 weeks, travelled $66,000 \mathrm{~km}$ and lifted a confined bubble of smoke and moisture to $35 \mathrm{~km}$ altitude. Its evolution was tracked by several satellite-based sensors and was successfully resolved by the European Centre for MediumRange Weather Forecasts operational system, primarily based on satellite data. Because wildfires are expected to increase in frequency and strength in a changing climate, we suggest that extraordinary events of this type may contribute significantly to the global stratospheric composition in the coming decades.

\footnotetext{
${ }^{1}$ Laboratoire Atmosphères, Milieux, Observations Spatiales, UMR CNRS 8190, IPSL, Sorbonne Univ./UVSQ, Guyancourt, France. ${ }^{2}$ Laboratoire de Météorologie Dynamique, UMR CNRS 8539, IPSL, PSL-ENS/Sorbonne Univ./Ecole Polytechnique, Paris, France. ${ }^{3}$ Laboratoire Interuniversitaire des Systèmes Atmosphériques, UMR CNRS 7583, IPSL, Université Paris-Est Créteil/Université de Paris, Créteil, France. ${ }^{4}$ European Centre for Medium-Range Weather Forecasts, Reading, UK. ${ }^{5}$ Institute of Space and Atmospheric Studies, University of Saskatchewan, Saskatoon, Canada. ${ }^{\bowtie}$ email: sergey.khaykin@latmos.ipsl.fr
} 
$\mathrm{T}$ he impact of wildfire-driven thunderstorms on the global stratosphere has been deemed small until the North American wildfires in August 2017. Pyro-cumulonimbus (pyroCb) clouds from that event caused stratospheric perturbations an order of magnitude larger than the previous benchmarks of extreme pyroCb activity and approached the effect of moderate volcanic eruption ${ }^{1,2}$. Volcanic eruptions inject ash and sulphur which is oxidized and condenses to form submicron-sized aerosol droplets in the stratosphere. With the PyroCb, intense fire-driven convection lifts combustion products in gaseous form as well as particulate matter including organic and black carbon, smoke aerosols and condensed water. The solar heating of the highly absorptive black carbon propels the smoke-laden air parcels upward $^{1}$, which, combined with horizontal transport ${ }^{3,4}$, leads to a more efficient meridional dispersion of these aerosols and prolongs their stratospheric residence time ${ }^{5}$.

The Australian bushfires that raged in December 2019-January 2020 have put a new benchmark on the magnitude of stratospheric perturbations. In this study, we use various satellite observations to quantify the magnitude of hemispheric-scale perturbation of stratospheric gaseous compounds and aerosol loading caused by these wildfires. The radiative forcing of the stratospheric smoke is estimated using a radiative transfer model supplied by satellite observations of aerosol optical properties. Finally, using the operational forecasting system of the European Centre for Medium-Range Weather Forecasts $(E C M W F)^{6}$ we show that the solar heating of an intense smoke patch has led to generation of a quasi-ellipsoidal anticyclonic vortex which lofted a confined bubble of carbonaceous aerosols and water vapour up to $35 \mathrm{~km}$ altitude in about 3 months.

\section{Results}

Large-scale perturbation of the stratosphere. The Australian wildfire season 2019/2020 was marked by an unprecedented burn area of 5.8 million hectares (21\% of Australia's temperate forests $)^{7}$ and exceptionally strong PyroCb activity in the southeast of the continent ${ }^{8}$. The strongest PyroCb outbreak occurred on the New Year's Eve (Fig. 1a) and on the 1st of January the instantaneous horizontal extent of the stratospheric cloud amounted to 2.5 million $\mathrm{km}^{2}$ as inferred from nadir-viewing TROPOMI $^{9}$ satellite measurement (Fig. 1b). On that day, an opaque cloud of smoke was detected in the stratosphere by the CALIOP space-based laser radar (lidar) ${ }^{10}$ at altitudes reaching $17.6 \mathrm{~km}$ (Fig. 2). Another PyroCb outbreak with stratospheric impact, although less vigorous, took place on 4 January 2020 and on 7 January, the horizontal extent of the stratospheric smoke cloud peaked at 6.1 million $\mathrm{km}^{2}$ (Fig. 1b) extending over much of the Southern midlatitudes (Fig. 2 and Supplementary Fig. 4c).

The high-altitude injections of smoke rapidly tripled the stratospheric aerosol optical depth (SAOD) in the southern extratropics. The SAOD perturbation has by far exceeded the effect on stratospheric aerosol load produced by the North American wildfires in 2017, putting the Australian event on par with the strongest volcanic eruptions in the last 25 years (Fig. 3), i.e. since the leveling off of stratospheric aerosol load after a major eruption of Mount Pinatubo in $1991^{11}$. Three months after the PyroCb event, the SAOD perturbation has remained at the volcanic levels, gradually decreasing with a rate similar to the decay of stratospheric aerosol produced by moderate volcanic eruptions.

Using aerosol extinction profiles retrieved from the limbviewing NASA OMPS-LP instrument ${ }^{12}$ we find the total aerosol particle mass lofted into the so-called stratospheric "overworld"13 (above $380 \mathrm{~K}$ isentropic level corresponding to $\sim 12-17 \mathrm{~km}$ altitude) is $0.4 \pm 0.2 \mathrm{Tg}$ (Fig. 4), which is nearly three times larger than the estimates for the previous record-high North American wildfires ${ }^{2}$. The increase in the stratospheric abundance of the gaseous combustion products, derived from the NASA

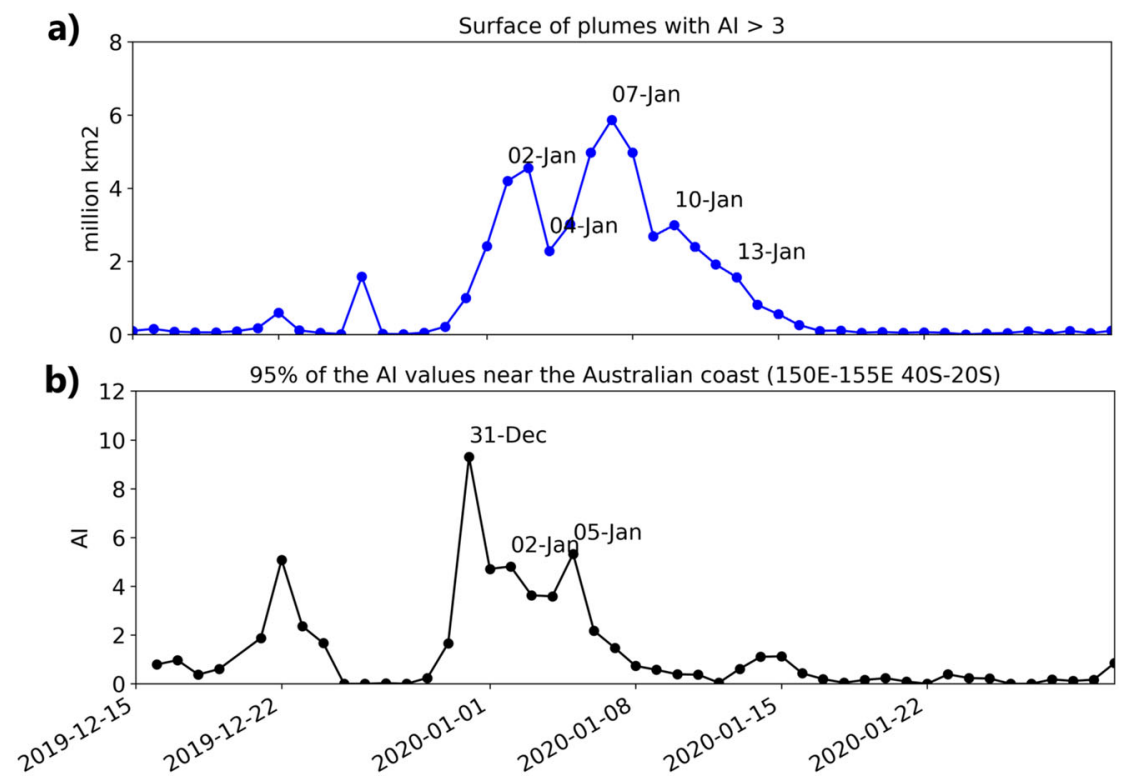

Fig. 1 Time evolution of the smoke clouds as observed by TROPOMI satellite instrument. a Time evolution of the total surface covered by the aerosol plumes with Absorbing Aerosol Index AAl>3 over the southern hemisphere. This threshold is chosen to follow the evolution of the main plume that was characterized by values of $\mathrm{Al}$ up to 10. The plumes show a sharp gradient in $\mathrm{Al}$ at the borders, where the $\mathrm{Al}$ value rapidly decreases, allowing to clearly define the boundaries of the aerosol cloud. $\mathbf{b}$ 95th percentile of the aerosol close to the Eastern Australian coastal region $\left(150^{\circ}-155 \mathrm{E} 20^{\circ}-40^{\circ} \mathrm{S}\right)$ where the extreme PyroCb activity took place. The main aerosol injections occurred between 30 and 31 December 2019, producing a plume that reached a first maximal spatial extension on the 2 January 2020, and between 4 and 5 January, when a second event produced an additional aerosol cloud that, combined with the first one, caused a total absorbing aerosol coverage that reached a maximum of 6 millions $\mathrm{km}^{2}$ of extension on the 7 January. The plumes then gradually dissipated and diluted, decreasing in their Al values, until the third week of January, when the Al signal from the aerosol clouds is no more visible by TROPOMI, with the exception of few bubbles of confined aerosol (see next sections). 


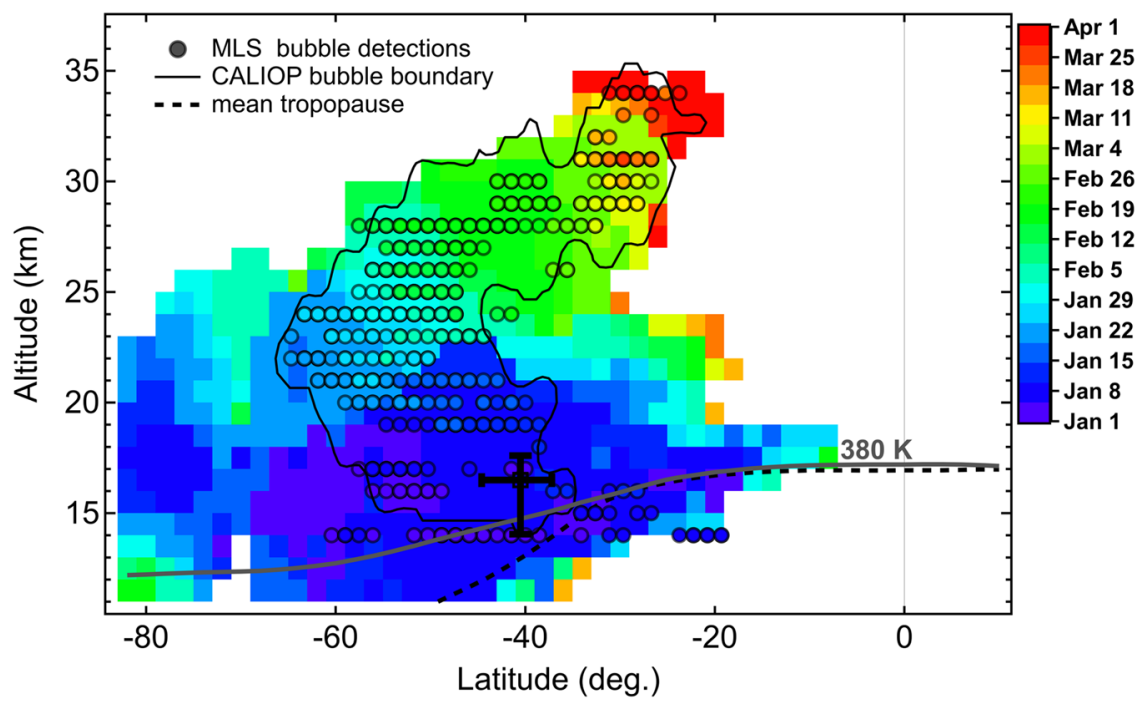

Fig. 2 Latitude-altitude evolution of the smoke plumes in the stratosphere. The pixels, colour coded by date, indicate doubling of aerosol extinction with respect to December 2019 levels for data where aerosol to molecular extinction ratio is 1 or higher. The black circles with date-colour filling indicate the locations of high amounts of water vapour and/or carbon monoxide detected by MLS (see "Methods"). The black contour encircles the locations of aerosol bubble detections by CALIOP lidar (see Fig. 5a and Supplementary Fig. 3). The cross marks the latitude-altitude extent of the stratospheric cloud detected by CALIOP on the 1st January (see Fig. 5a). The grey solid and black dashed curves indicate respectively the zonal-mean $380 \mathrm{~K}$ isentrope and the lapse-rate tropopause for the January-March 2020 period.

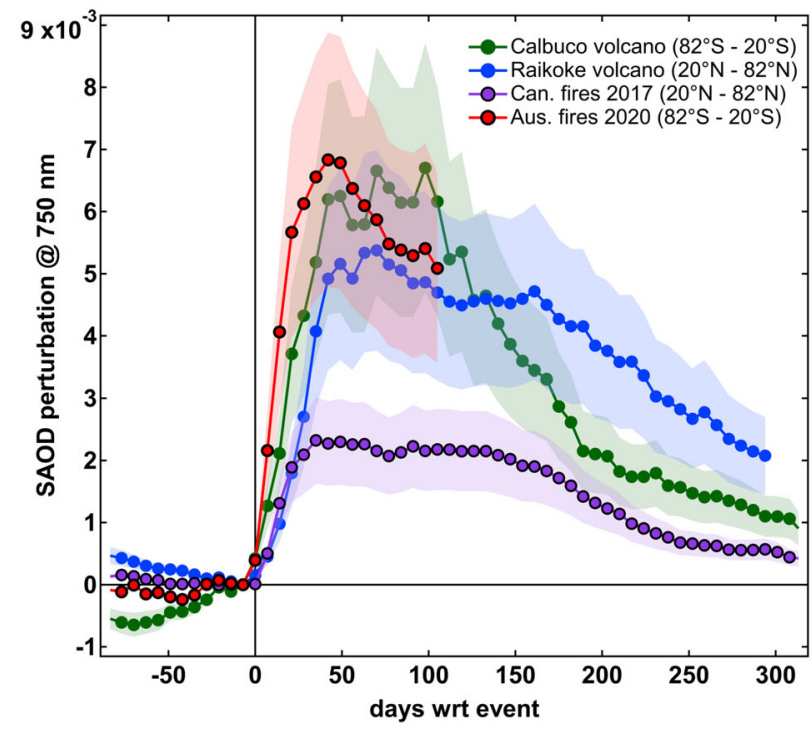

Fig. 3 Perturbation of the stratospheric aerosol optical depth (SAOD) due to Australian fires and the strongest events since 1991. The curves represent the SAOD perturbation at $746 \mathrm{~nm}$ following the Australian wildfires, the previous record-breaking Canadian wildfires in 2017 and the strongest volcanic eruptions in the last 29 years (eruptions of Calbuco volcano in 2015 and Raikoke volcano in 2019 [ref. ${ }^{41}$ ]). The time series are computed from OMPS-LP aerosol extinction profiles as weekly-mean departures of aerosol optical depth above $380 \mathrm{~K}$ isentropic level (see Fig. 2) from the levels on the week preceding the event. The weekly averages are computed over equivalent-area latitude bands (as indicated in the panel) roughly corresponding to the meridional extent of stratospheric aerosol perturbation for each event. The shading indicates a $30 \%$ uncertainty in the calculated SAOD, as estimated from SAGE III coincident comparisons (See Methods).

Microwave Limb Sounder (MLS) satellite observations ${ }^{14}$, is as remarkable as the aerosol increase. Figure 4 puts in evidence that the stratospheric masses of carbon monoxide (CO) and acetonitrile $\left(\mathrm{CH}_{3} \mathrm{CN}\right)$ bounded within the southern extratropics

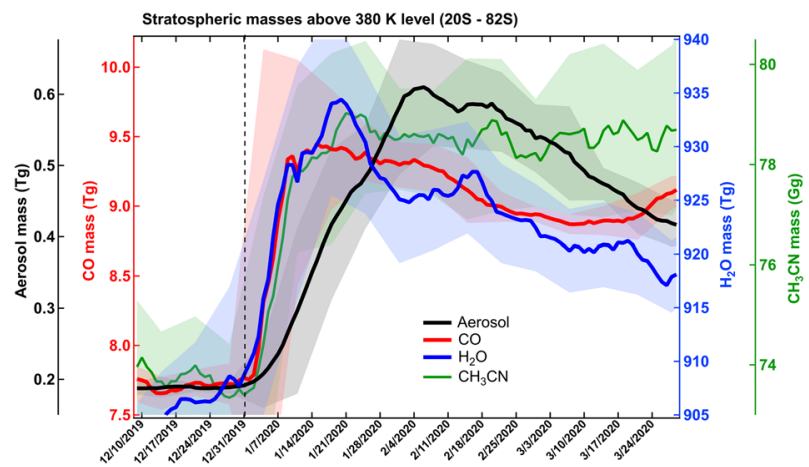

Fig. 4 Time evolution of the daily total mass of $\mathrm{CO}, \mathrm{CH}_{3} \mathrm{CN}, \mathrm{H}_{2} \mathrm{O}$ and aerosols above the $380 \mathrm{~K}$ potential temperature, between $20^{\circ} \mathrm{S}$ and $82{ }^{\circ} \mathrm{S}$. The dotted and solid lines correspond to daily data and 1-week smoothed data, respectively. Envelopes represent two standard deviations over the 1week window (see "Methods"). As shown in this figure, the levels of $\mathrm{CO}$, $\mathrm{CH}_{3} \mathrm{CN}, \mathrm{H}_{2} \mathrm{O}$, and aerosols started to increase simultaneously and kept increasing during $~ 2-3$ weeks, a duration corresponding probably to the time taken by products injected in the lowermost stratosphere to ascend above $380 \mathrm{~K}$. The stratospheric masses of carbon monoxide (CO) and acetonitrile $\left(\mathrm{CH}_{3} \mathrm{CN}\right)$ bounded within the southern extratropics increase abruptly by $1.5 \pm 0.9 \mathrm{Tg}$ and $3.7 \pm 2.0 \mathrm{Gg}$, respectively during the first week of 2020 . This gives a $\mathrm{CO} / \mathrm{CH}_{3} \mathrm{CN}$ mass ratio of 0.0025 , consistently with previous estimates for temperate Australian wildfires ${ }^{42}$. The injected mass of water was estimated at $27 \pm 10 \mathrm{Tg}$ that is about $3 \%$ of the total mass of stratospheric overworld water vapour in the southern extratropics. The shading shows that the amplitude of fluctuations increases sharply during the sharp rise of species masses, reflecting the fact that sampling of the bubble by MLS is more random than on a more homogeneous field. The lagging increase of the aerosol mass is due to the fact that the OMPS-LP extinction retrieval saturates at extinction values above $0.01 \mathrm{~km}^{-1}$. Profiles are, therefore, truncated below any altitude exceeding this value, which can lead to an underestimation of the early aerosol plume when it is at its thickest. This artifact, which explains the slower increase of aerosol mass than gases, persists until mid-February when the plume is sufficiently dispersed so that OMPS-LP extinction measurements no longer saturate. 
increase abruptly by $1.5 \pm 0.9 \mathrm{Tg}(\sim 20 \%$ of the pre-event levels) and $3.7 \pm 2.0 \mathrm{Gg}(\sim 5 \%)$, respectively, during the first week of 2020. The injected mass of water was estimated at $27 \pm 10 \mathrm{Tg}$ that is about $3 \%$ of the total mass of stratospheric overworld water vapour in the southern extratropics (see "Methods").

The gases and particles injected by the PyroCbs were advected by the prevailing westerly winds in the lower stratosphere. The patches of smoke dispersed across all of the Southern hemisphere extratropics in less than two weeks with the fastest patches returning back over Australia by 13 January 2020, whereas the carbon-rich core remained bounded within midlatitudes as shown in Fig. 2. During the following months, most of the particulate material dwelled in the lower stratosphere, the larger and heavier particles sedimented to lower altitudes while the carbon-rich fraction ascended from 15 to $35 \mathrm{~km}$ due to solar heating of black carbon (Supplementary Fig. 1).

Radiative forcing. The large amount of aerosols produced a significant radiative forcing (RF), which we quantified using explicit radiative transfer modelling based on the measured aerosol optical properties (Supplementary notes 1). In the latitude band between 25 and $60^{\circ} \mathrm{S}$, an average cloud-free reference monthly radiative forcing as large as about $-1.0 \mathrm{~W} / \mathrm{m}^{2}$ at the top of the atmosphere (TOA) and $-3.0 \mathrm{~W} / \mathrm{m}^{2}$ at the surface is found in February 2020 (Supplementary Fig. 2). This can be attributed to perturbation to the stratospheric aerosol layer by the Australian fires plumes. The area-weighted global-equivalent cloudfree RF is estimated (Supplementary Table 1) to values as large as $-0.31 \pm 0.09 \mathrm{~W} / \mathrm{m}^{2}$ (TOA) and $-0.98 \pm 0.17 \mathrm{~W} / \mathrm{m}^{2}$ (at the surface). It is important to notice that these estimations don't take the presence of clouds into account and are to be taken as purely reference values. For typical average cloud cover in the area affected by the plume ${ }^{15}$, the surface all-sky RF can be reduced to $\sim 50 \%$ and the TOA all-sky RF to $\sim 30-50 \%$ of the clear-sky RF estimations $^{16}$ (see Supplementary notes 1 for details). From the perspective of the stratospheric aerosol layer perturbation, the global TOA RF produced by the Australian fires 2019/2020 is larger than the RF produced by all documented wildfire events and of the same order of magnitude of moderate volcanic eruptions during the last three decades (that have an integrated effect estimated at ${ }^{17}-0.19 \pm 0.09 \mathrm{~W} / \mathrm{m}^{2}$, or smaller $\left.{ }^{18}\right)$. In contrast to the non-absorbing volcanic sulphates, the carbonaceous wildfire aerosols absorb the incoming solar radiation, leading to yet more substantial radiative forcing at the surface, due to the additional large amount of energy absorbed in the plume. This can be linked to the ascent of a smoke cloud in the stratosphere, which is dicussed in the next section.

Rising bubble of smoke. The primary patch of smoke originating from the New Year's Eve PyroCb event followed an extraordinary dynamical evolution. By the 4 January 2020, en route across the Southern Pacific, the core plume started to encapsulate into a compact bubble-like structure, which was identified using CALIOP observations on 7 January 2020 as an isolated $4-\mathrm{km}$ tall and $1000 \mathrm{~km}$ wide structure (Fig. 5a). Over the next 3 months, this smoke bubble crossed the Pacific and hovered above the tip of South America for a week. It then followed a 10-week westbound round-the-world journey that could be tracked until the beginning of April 2020 (Supplementary notes 2 and Supplementary Fig. 3), travelling over 66,000 km.

The large amount of sunlight-absorbing black carbon contained in the smoke cloud provided a localized heating that forced a)

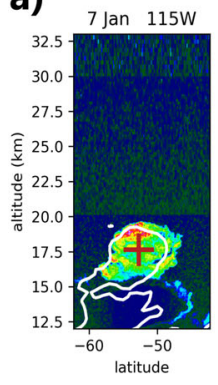

b)

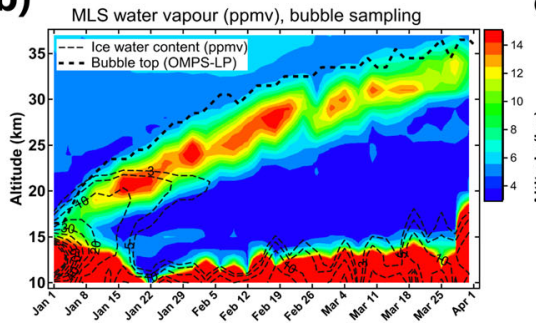

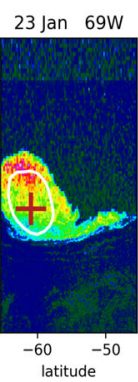

c)

MLS carbon monoxide (ppbv), bubble sampling

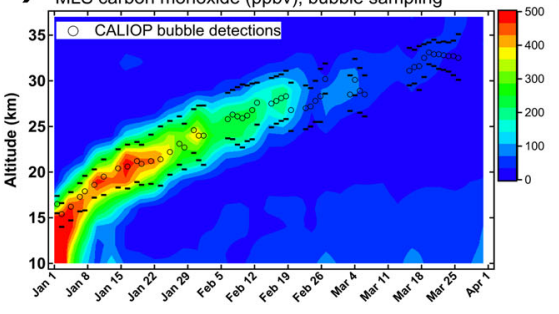

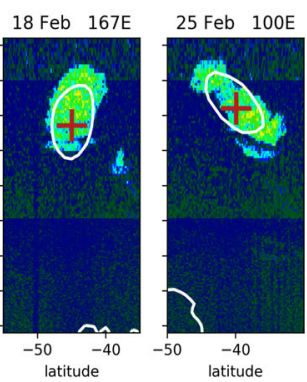

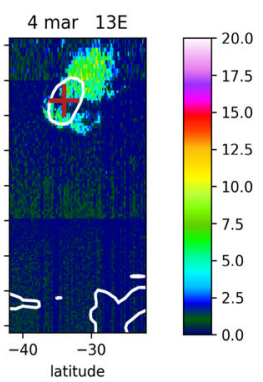

d)

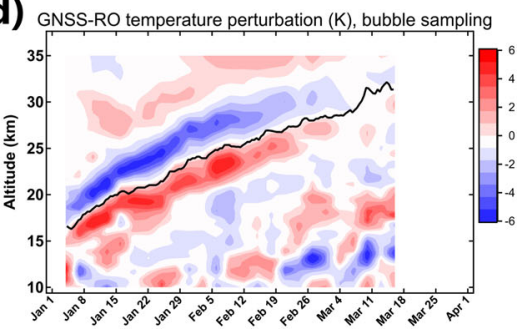

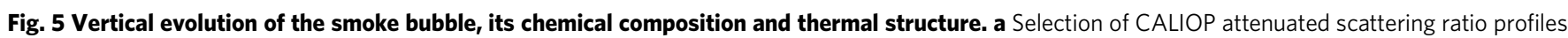
for clear intersections of the bubble by the orbit except the first panel of 1st of January that shows the dense and compact plume on its first day in the stratosphere. The attenuated scattering ratio is calculated by dividing the attenuated backscattering coefficient by the calculated molecular backscattering. The data are further filtered horizontally by an 81-pixel moving median filter to remove the noise. The crosses show the projected interpolated location of the vortex vorticity centroid from the ECMWF operational analysis onto the orbit plane at the same time and the white contour shows the projected contour of the half maximum vorticity value in the pane passing by the vortex centroid and parallel to the orbit plane (see Fig. 6). $\mathbf{b}$ Evolution of the water vapour mixing ratio within the rising bubble based on MLS bubble detections (see "Methods"). The dashed contours show the equivalent mixing ratio of ice water derived from MLS ice water content vertical profiles collocated with the bubble. The thick dashed curve marks the top altitude of the aerosol bubble determined as the level where OMPS-LP extinction triples that of the nearest upper altitude level. c Evolution of carbon monoxide (MLS) within the bubble. The centroid and the vertical boundaries of the aerosol bubble determined using CALIOP data are overplotted as circles and bars respectively. $\mathbf{d}$ Composited temperature perturbation within the smoke bubble from Metop GNSS radio occultation (RO) temperature profiles collocated with the smoke bubble (see "Methods"). The black line shows the centroid of vortex detected from ECMWF data (see Supplementary notes 4.1 and Supplementary Fig. 7 b). 
a)

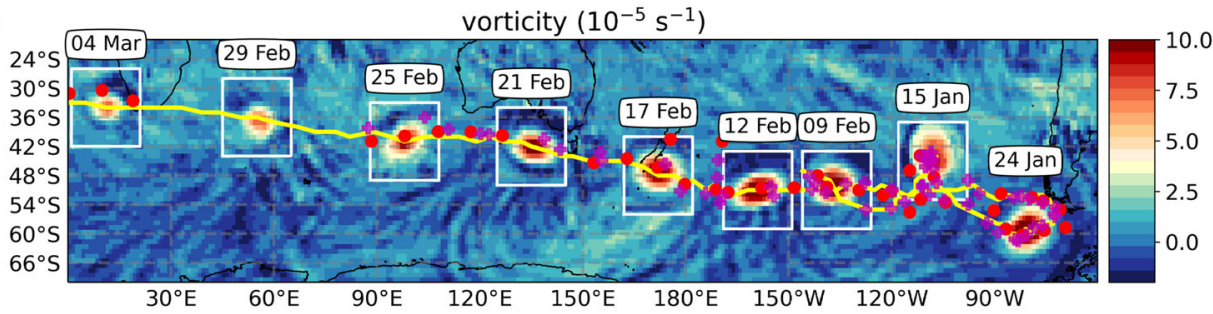

b) vorticity $\left(10^{-5} \mathrm{~s}^{-1}\right)$
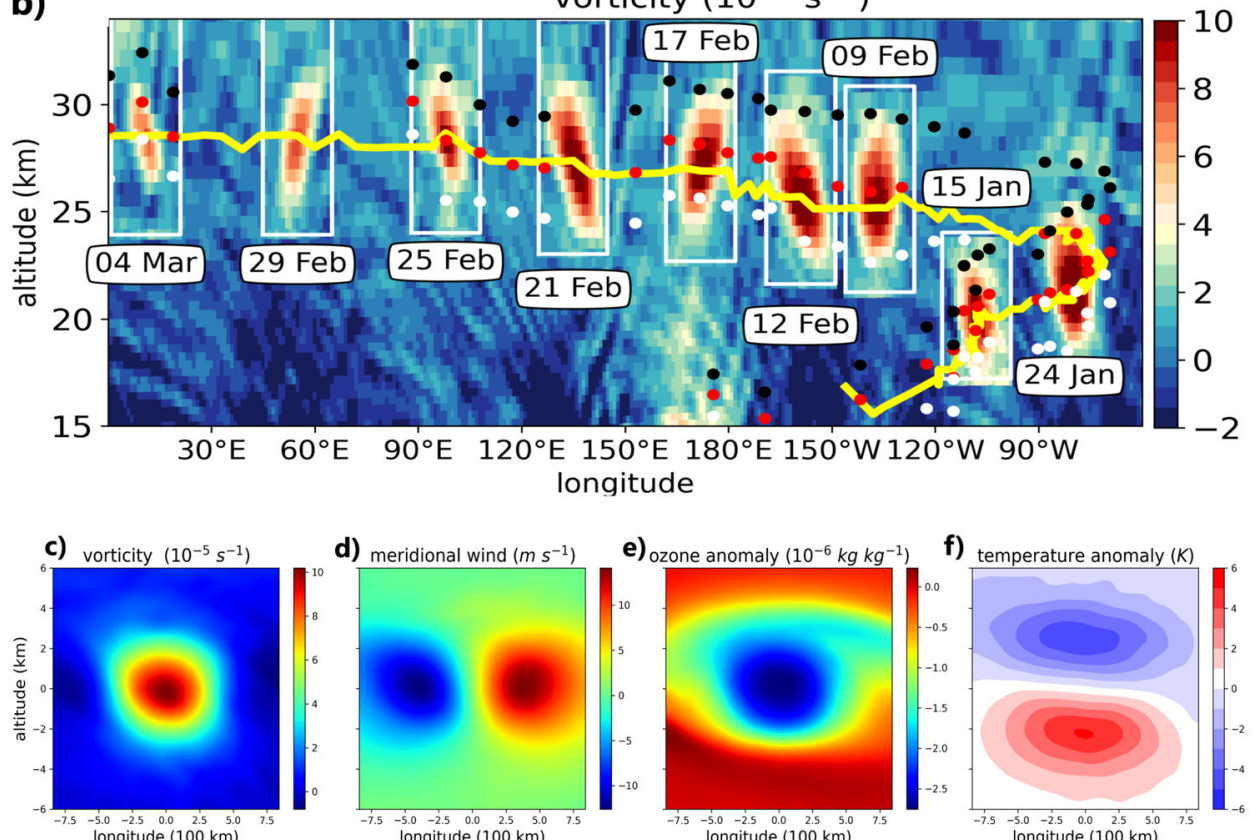

Fig. 6 Spatiotemporal evolution of the vortex and its thermodynamical properties. a Composite horizontal sections of the vortex. The background shows the relative vorticity field on 24 January 2020 6UTC from the ECMWF operational analysis on the surface $46.5 \mathrm{hPa}$ ( $21.3 \mathrm{~km}$ at the location of the vortex) corresponding to the level of highest vorticity in the vortex. The boxes show the vorticity field at other times as horizontal sections at the level of maximum vorticity centroid projected onto the background field. The yellow curve is the twice-daily sampled trajectory of the vortex centroid. The red dots show the location of the CALIOP bubble centroid for all the cases where it is clearly intersected by the orbit. The magenta crosses show the location of the center of the compact aerosol index anomaly as seen from TROPOMI (Supplementary notes 3). b Composite vertical section of the vortex. The background is here the longitude-altitude section of the vortex on 24 January 20206 UTC at the latitude $47^{\circ} \mathrm{S}$. The boxes show vertical sections at the same time as (a) at the latitude of maximum vorticity. The black, red and white dots show, respectively, the CALIOP bubble top, centroid and bottom. c Composite of the vortex vorticity in the longitude-altitude plane at the level and at the latitude of the vortex centroid performed during the most active period of the vortex between 14 January and 22 February. $\mathbf{d}$ Same as (c) for the meridional wind deviation with respect to the mean in the displayed box. e Same as (c) but for the ozone mixing ratio deviation with respect to the zonal mean. $\mathbf{f}$ Same as (c) but for the temperature deviation with respect to the zonal mean.

the air mass to rise through the stratosphere. With an initial ascent rate of about $0.45 \mathrm{~km} /$ day, the bubble of aerosol continuously ascended during the three months with an average rate of $0.2 \mathrm{~km} /$ day. While remaining compact, the bubble was leaking material from its bottom part, leaving an aerosol trail that was progressively dispersed and diluted, filling the whole midlatitude austral stratosphere up to $30 \mathrm{~km}$ (Supplementary Fig. 1, see also Fig. 10b). The rise ceased in late March 2020 when the top of the bubble reached $36 \mathrm{~km}$ altitude (Fig. $5 \mathrm{~b}$ and Supplementary Fig. 3). This is substantially higher than any coherent volcanic aerosol or smoke plume observed since the major eruption of Pinatubo in 1991.

Along with the carbonaceous aerosols, the bubble entrained tropospheric moisture in the form of ice aggregates injected by the overshooting PyroCbs. In the warmer stratosphere, the ice (detected by MLS sensor as high as $22 \mathrm{~km}$, cf. Figure 5b) eventually evaporated, enriching the air mass with water vapour. This led to extraordinary high water vapour mixing ratios emerging across the stratosphere within the rising smoke bubble (Fig. 5b). The decay of $\mathrm{CO}$ within the bubble (Fig. 5c) was faster than that of water vapour, reflecting the fact that, unlike water vapour, the carbon monoxide was subject to photochemical oxidation whose efficiency increases sharply with altitude ${ }^{19}$.

Temperature profiles from GNSS radio occultation sensors exhibit a clear dipolar anomaly within the bubble with a warm pole at its bottom and a cold pole at its top (Fig. 5d). Although counterintuitive from the pure radiative transfer perspective, the observed temperature dipole within the heated cloud represents an expected thermal signature of a synoptic-scale vortex.

The vortex. The compact shape of the smoke bubble could only be maintained through an efficient confinement process. The meteorological analysis of the real-time operational ECMWF integrated forecasting system (IFS) ${ }^{6}$ reveals that a localized anticyclonic vortex was associated with the smoke bubble during all its travel, moving and rising with it (Figs. 5, 6a, b and Supplementary Fig. 5). With a peak vorticity of $10^{-4} \mathrm{~s}^{-1}$ (Figs. 6c, 7b) and a maximum anomalous wind speed of $13 \mathrm{~m} \mathrm{~s}^{-1}$ (Fig. 6d) during most of its lifetime, the vortex had a turnover time of 

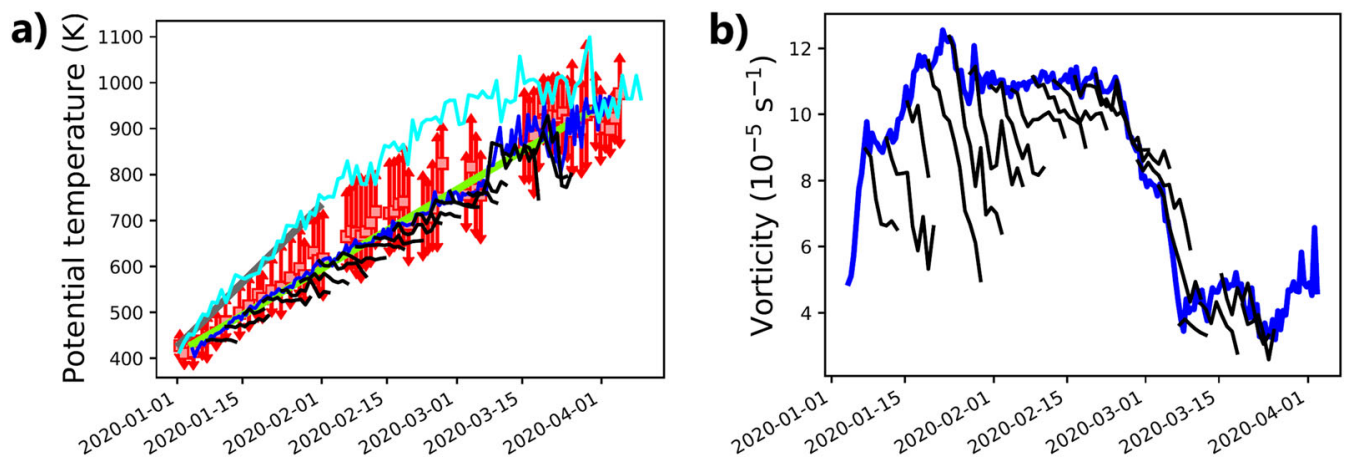

Fig. 7 Time evolution of the altitude and vorticity of the main vortex. The two panels show the potential temperature (a) and vorticity (b) as a function of time. All the quantities are defined at the vortex centroid where the vorticity is maximum. In a the red squares show the position of the aerosol bubble centroid according to CALIOP. The CALIOP centroid is defined by averaging the most extreme top, bottom, south and north edges. The arrows show the extension of the bubble in potential temperature space. The cyan line shows the upper envelope of the bubble as detected by OMPS-LP, the green line is a linear fit to the ascent of the vortex and the grey line shows a $10 \mathrm{~K}$ day ${ }^{-1}$ curve. In $\mathbf{a}$, $\mathbf{b}$, the black lines show the ECMWF 10 -day forecast evolution, plotted every four days. The forecast evolution is only shown for the period where it maintains the vortex. The slight discrepancy between the analysis and the initial point of the forecast is because the 10-day forecast is produced from a slightly inferior 6-h analysis, due to real time constraints.

about $36 \mathrm{~h}$. It has therefore survived about 60 turnover times demonstrating a remarkable stability and resilience against perturbations. The ascent was surprisingly linear in potential temperature at a rate of $5.94 \pm 0.07 \mathrm{~K} \mathrm{day}^{-1}$ (Fig. 7a). This corresponds to a heating rate $d T / d t$ which varies from about $3 \mathrm{~K}$ day ${ }^{-1}$ at the beginning of January to $1.5 \mathrm{~K} \mathrm{day}^{-1}$ at the end of March. The altitude rise is from 16 to $33 \mathrm{~km}$ for the vortex centroid and from 17 to $36 \mathrm{~km}$ for the top of the bubble according to CALIOP. The upper envelope of the OMPS detection of the bubble is seen as the cyan curve on Fig. 7a. This envelope is always above the top detected from CALIOP. Such a bias is expected as OMPS-LP is a limb instrument that scans a much wider area than the narrow CALIOP track. Both CALIOP and OMPS-LP detect that the top of the bubble rises initially faster than the vortex core, by about $10 \mathrm{~K} \mathrm{day}^{-1}$. This period corresponds to the initial travel of the bubble to the tip of South America. In terms of altitude ascent, the rates 10 and $5.94 \mathrm{~K}$ day $^{-1}$ translate approximately as 0.45 and $0.2 \mathrm{~km} \mathrm{day}^{-1}$.

The confining properties of the vortex are confirmed by the colocated anomalies in tracers and aerosol from the TROPOMI instrument. The satellite observations (Supplementary notes 3.3 and Supplementary Fig. 4a, b) reveals an isolated enhancement of the aerosol absorbing index and of the CO columnar content, as well as the presence of a deep mini ozone hole, depleted by up to 100 DU. All three features were captured in the same position by the ECMWF analyses (Fig. 6e and Supplementary Figs. 4 and 7).

Companion vortices. It is worth noticing that the vortex was not a single event. It had several companions, albeit of smaller magnitude and duration, also caused by localized smoke clouds. The most noticeable lasted one month and travelled the hemisphere. Another one found a path across Antarctica where it was subject to the strong aerosol heating of permanent daylight and rose up to $27 \mathrm{~km}$.

The second vortex is borne from the smoke cloud that found its way to the stratosphere during the PyroCb event of 4-5 January 2020. This cloud initially travelled north east passing north of New Zealand before taking a south easterly direction crossing the path of the cloud emitted on 31 December 2019 and the main vortex. Fig. $8 \mathrm{a}$, b shows that a vortex-like structure can be spotted as early as 7 January, coinciding with the location of a compact bubble according to CALIOP. Subsequently, the bubble crossed the path of the first vortex on 16 January while rising and intensifying (see Fig. 8c, d) and travelled straight eastward crossing the Atlantic and the Indian Ocean until it reached the longitude of Australia by the end of January where it disappeared after travelling all the way round the globe. During this travel, the altitude of the vortex centroid rose from 15 to $19 \mathrm{~km}$ and the top of the bubble, as seen from CALIOP, reaches up to $20 \mathrm{~km}$.

The third bubble has been first detected by CALIOP on 7 January at $69^{\circ} \mathrm{S} / 160^{\circ} \mathrm{W}$. It then moved over Antarctica (Fig. 9a) until the end of January where it spent a week over the Antarctic Peninsula before moving to the tip of South America, shortly after this region was visited by the main vortex. It eventually moved to the Atlantic where it dissipated by 25 February (Fig. 9b). The bubble was accompanied by a vortex during its whole life cycle as seen in Fig. 9c. Although the magnitude of this vortex was modest compared to the main one and even the second one in terms of maximum vorticity (Fig. 9e), it performed a very significant ascent from 18 to $26 \mathrm{~km}$ (Fig. 9d). We attribute this effect to the very effective aerosol heating received during the essentially permanent daylight of the first period over Antarctica. The simultaneous rise of the main vortex and the third vortex is very clear from the OMPS-LP latitude-altitude sections in Fig. 10c, d.

The combined trajectories of the main vortex and its two companions are shown in Fig. 10e. Figure 10a shows how the trajectories of the vortices form the skeleton of the dispersion path of the smoke plume in the stratosphere.

Figure 10b shows that OMPS-LP follows closely the evolution of the top altitude of all the vortices under the shape of welldefined branches in a longitude-time Hovmöller diagram. It is worth noticing that both the main and the third vortex spent some time wandering in the vicinity of the Drake passage at the beginning of February. Such a stagnation situation is prone to sensitivity. The IFS forecasts during the end of January predicted that the main vortex would cross to the Atlantic, while instead it did not and began moving westward over the Pacific as it reached a higher altitude where easterly winds prevail. Several secondary branches that seem to separate from the main one followed by the main vortex are also visible in this diagram. A detailed inspection reveals that they are indeed associated with patches left behind by the main bubble as it moved upward. It is apparent from several of the panels of Fig. 7a that the top part of the bubble remained always compact while the bottom part was constantly leaking material. Figure 10c, d shows latitude-altitude cross sections of OMPS aerosols on 16 January and 1 February. The fast rise of the main vortex during that period is visible near $50 \mathrm{~S}$ while the second vortex is located at lower altitude and the third vortex corresponds to the towering structure by $75-80$ S. 
a)
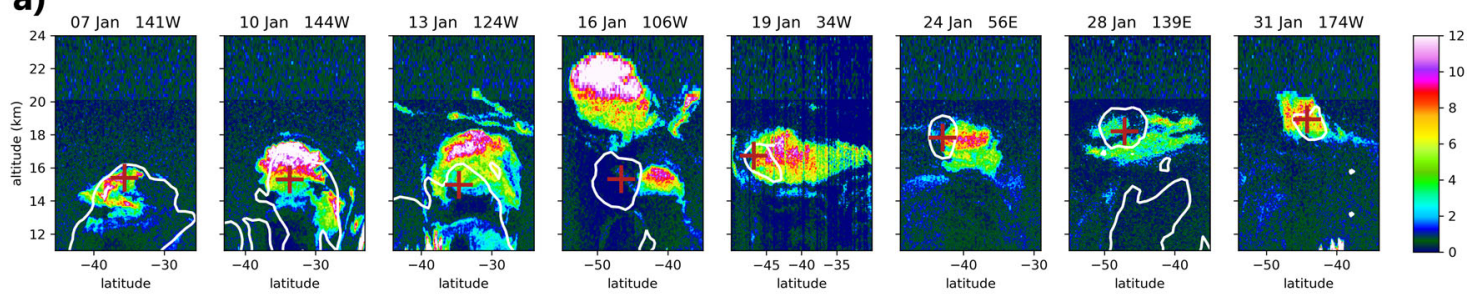

b)
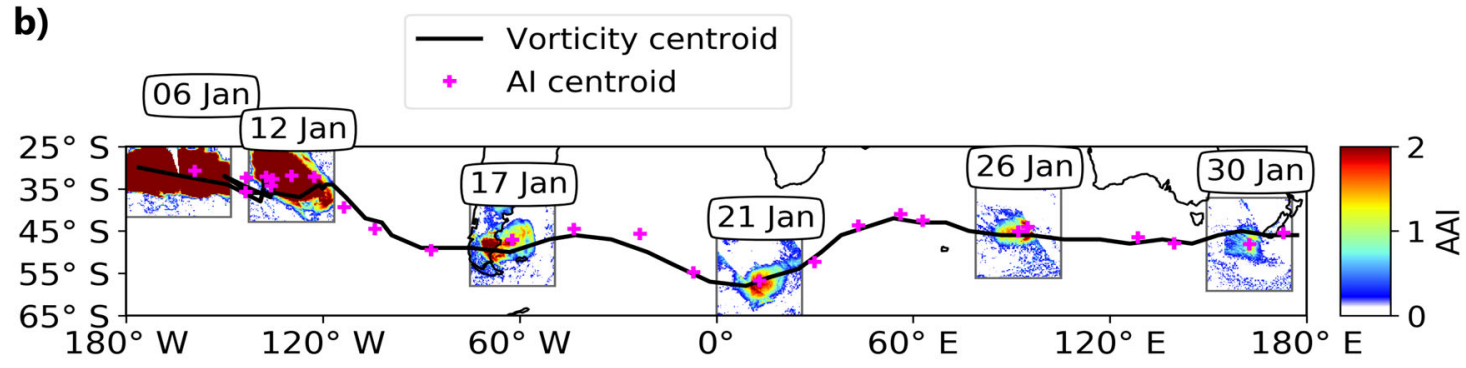

c)

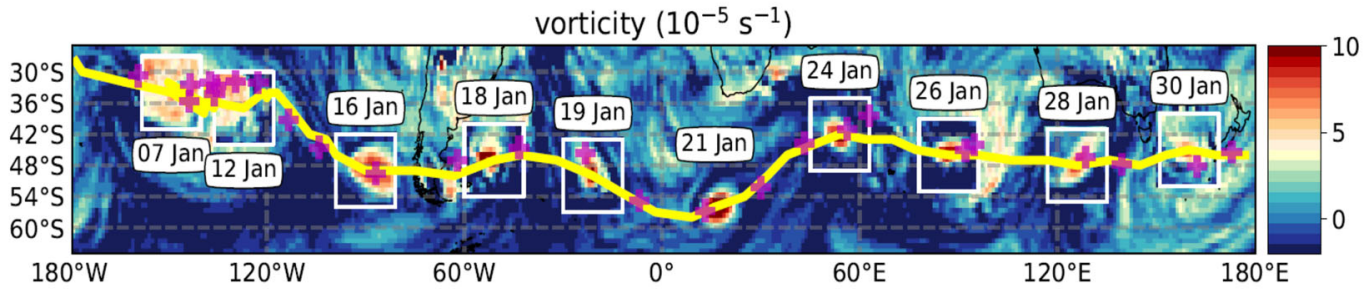

d)

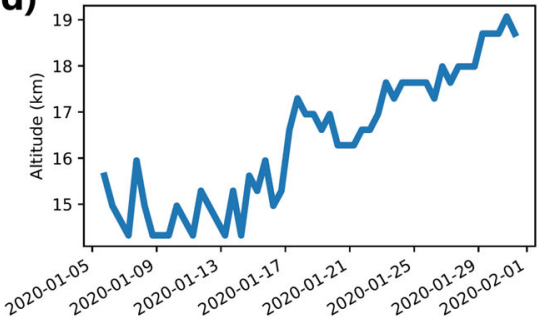

e)

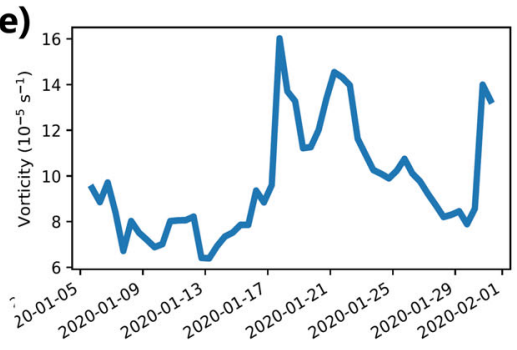

Fig. 8 Spatiotemporal evolution of the second vortex. a Time evolution from eight matching sections of CALIOP. b Composite of TROPOMI aerosol index $\mathrm{AI}$ ) at the location of the vortex for six dates that do not necessarily match that of CALIOP. c Time evolution of the vortex according the ECMWF analysis from ten vorticity snapshots at the level of maximum vorticity. The background is shown for 24 January. In $\mathbf{b}$, c the trajectory of the Al centroid is shown as

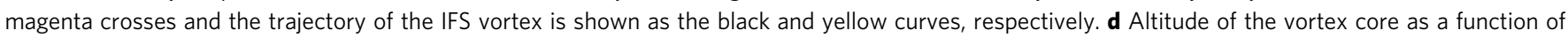
time. e Maximum vorticity at the vortex core as a function of time.

\section{Discussion}

Long-lived anticyclones have also been observed as very rare events in the summer Arctic stratosphere ${ }^{20-22}$, but they are much larger structures of about $2000 \mathrm{~km}$, very near the pole, and do not display any of the specific characters of the self-generated smokecharged vortex. According to geophysical fluid dynamics theory $^{23}$, a local heating in the austral stratosphere is expected to produce positive potential vorticity aloft and destroy it beneath. The positive potential vorticity is partially realized as anticyclonic rotation and partially as temperature stratification. The negative potential vorticity is apparently dispersed away with the tail of the bubble. The ECMWF analysed thermal structure (Fig. $6 \mathrm{f}$ and Supplementary Fig. 7c) shows the same dipole as in the GNSS-RO satellite profiles with the same amplitude. The observed vortex is quite similar to known isolated ellipsoidal solutions of the quasigeostrophic equations ${ }^{24}$ which explain some of the long-lived vortices in the ocean ${ }^{25}$, but such a structure is described here for the first time in the atmosphere.

The ECMWF analysis uses climatological aerosol fields, so it does not take the aerosol emissions by the Australian wildfires into account, nor the satellite measurements of aerosol extinction. Thus, the replication of the vortex by the analysis was due to assimilation of temperature, wind and ozone measurements from operational satellites. We found that the radio-occultation temperature profiling satellite constellation played the key role in the successful reconstruction of this unusual stratospheric phenomenon by ECMWF analyses (Supplementary notes 4.2). The analyses were also influenced by a few radiosonde profiles and wind profiles in the lower stratosphere by the ESA Aeolus satellite's Doppler wind lidar ${ }^{26}$, which provided an observational evidence of the anticyclonic vortex.

The ECMWF IFS produce analyses using a 4-dimensional variational data assimilation method ${ }^{27}$, combined with a highresolution time-evolving forecast model that predicts the atmospheric dynamics. The assimilation system updates the state of the atmosphere using satellite data and in situ observations. As aerosols are not assimilated in the IFS, the ECMWF forecast was not expected to maintain the vortex as observed. Indeed, as shown in Fig. 7a, b, the forecast consistently predicts a decay of the vortex amplitude and fails to predict its rise except on 3rd 
a)
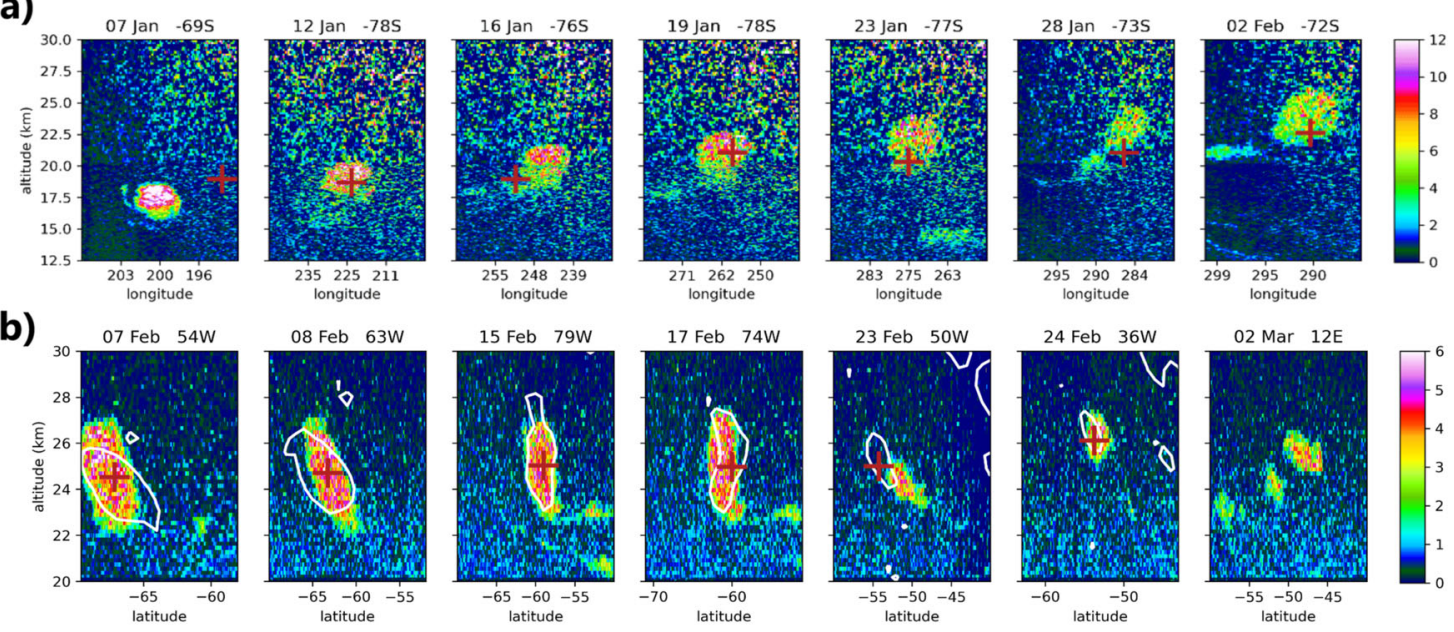

c)

$$
\text { vorticity }\left(10^{-5} \mathrm{~s}^{-1}\right)
$$

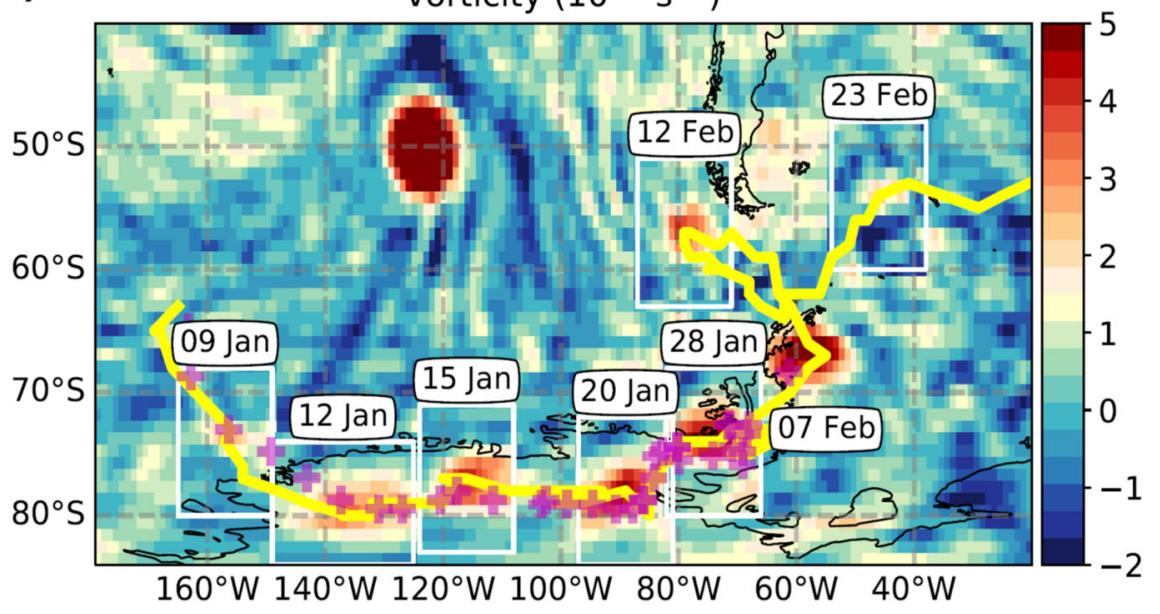

d)

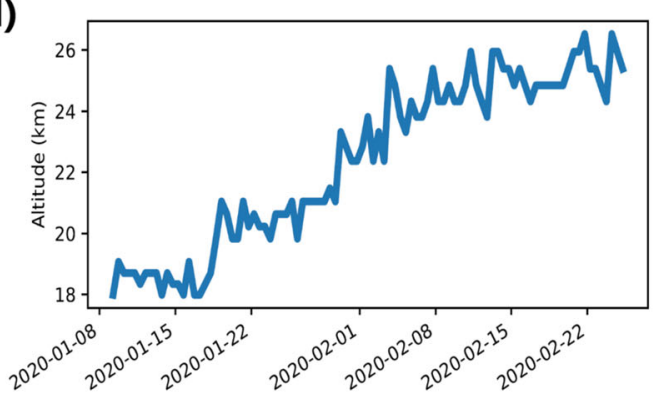

e)

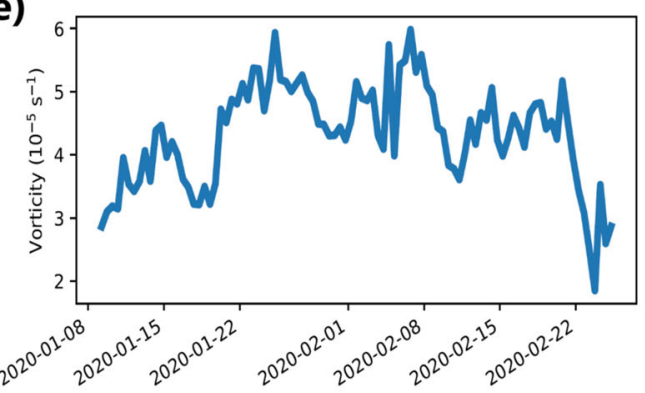

Fig. 9 Spatiotemporal evolution of the third vortex. a Time evolution of the vortex from 7 matching sections of CALIOP during its first period over Antarctica. We use here daily orbits of CALIOP, hence the high level of noise. The $x$-axis is mapped over longitude due to the proximity of the pole. $\mathbf{b}$ Time evolution of the third vortex from 7 matching sections of CALIOP during its second period. $\mathbf{c}$ Time evolution of the vortex according the ECMWF analysis from eight vorticity snapshots at the level of maximum vorticity. The background is shown for 7 February where the main vortex is also visible. The yellow curve shows the trajectory of the vortex in the IFS, the magenta crosses mark the TROPOMI AI centroid. $\mathbf{d}$ Altitude of the vortex core as a function of time. e Maximum vorticity of the vortex core as a function of time.

March where the vorticity centroid underwent a jump following the stretching and breaking of the vortex under the effect of vertical shear a few days earlier. As the nature of this event was purely dynamical, it was correctly predicted. This trend would lead to a rapid loss of the vortex and is corrected by the assimilation of new observations, providing an additional forcing that ensures maintenance and rise of the structure.

The ozone hole is forced by the assimilation of satellite observations of ozone (Supplementary Fig. 6b, f). The physical mechanism leading to the ozone hole must be a combination of the uplift of ozone-poor tropospheric air and ozone-depleting chemistry in the smoke cloud.

The generation of the smoke-charged vortex is reported in another study ${ }^{28}$, of which we were made aware during the review process. They used MLS, OMPS and CALIOP satellite instruments as well as the US Navy Global Environmental Model (NAVGEM) analysis to characterize the evolution of chemical composition and structure of the main vortex until 10th March 

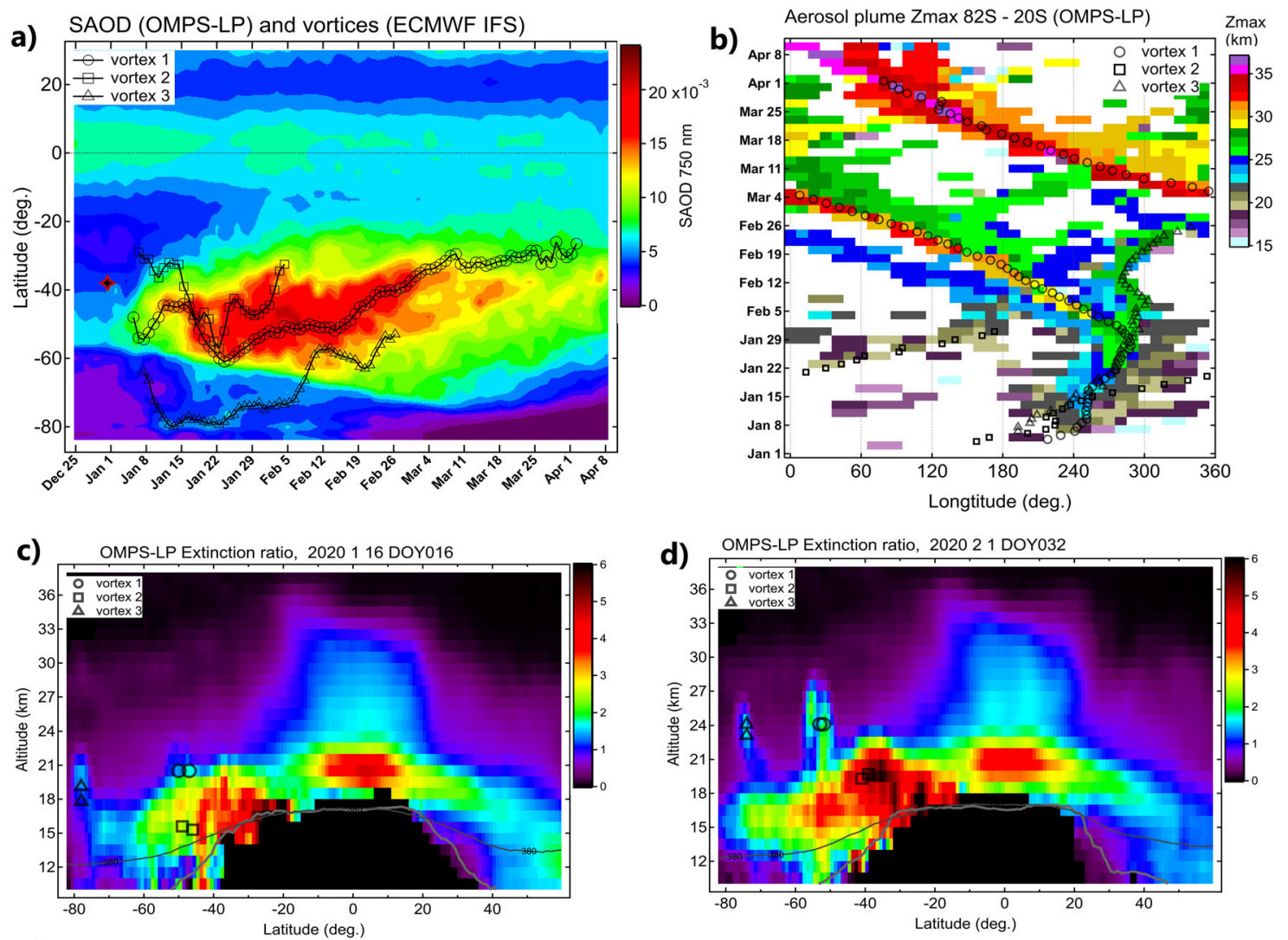

e)

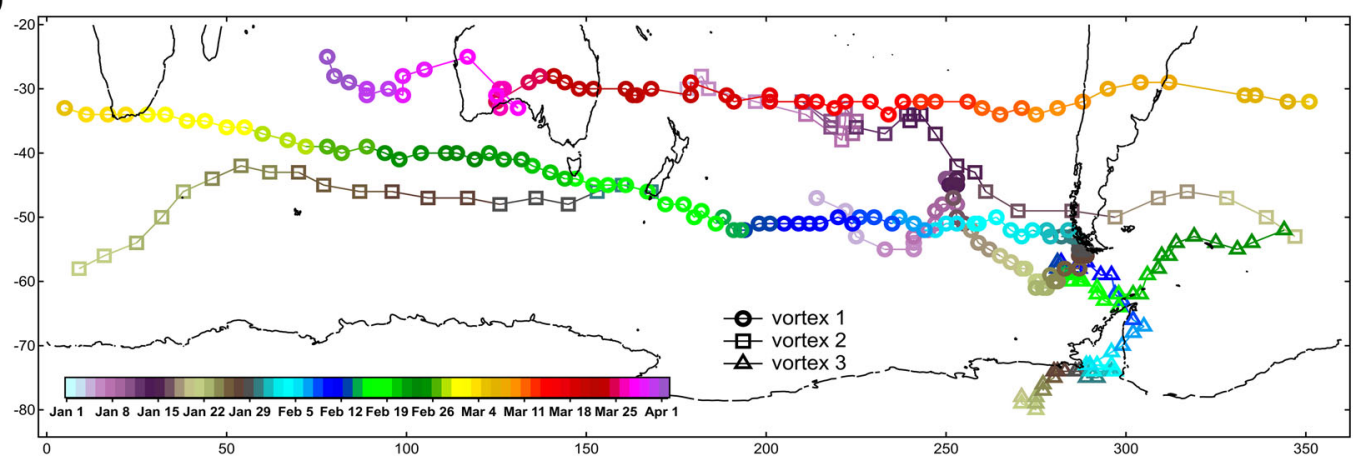

Fig. 10 Three-dimensional evolution of the three vortices from OMPS-LP and ECMWF IFS. a Time-latitude section of zonal-mean stratospheric aerosol optical depth (above the tropopause) from OMPS-LP measurements. The markers show locations of smoke-charged vortices identified using ECMWF vorticity fields. b Longitude-temporal evolution (Hovmöller diagram) of the maximum altitude of smoke plume inferred from OMPS-LP extinction data within $30^{\circ} \mathrm{S}-60^{\circ}$ above $15 \mathrm{~km}$ where aerosol to molecular extinction ratio exceeds 5 . The markers indicate the locations of the smoke-charged vortices identified using ECMWF vorticity fields. c Latitude-altitude section of zonal-mean aerosol to molecular extinction ratio above the local tropopause from OMPS-LP measurements for 16 January 2020. The thick and the thin curves indicate, respectfully, the zonal-mean lapse-rate tropopause and the $380 \mathrm{~K}$ potential temperature level. The markers show the positions of the main vortex and of the two companion vortices. d Same as (c) for 1 February 2020 . e Trajectories of the three vortices with colour-coded date in the longitude-latitude plane.

2020 , that is three weeks before it has reached its apogee and collapsed. Our analysis not only covers the entire lifetime of all the smoke-generated vortices, but provides a more comprehensive description of their dynamical evolution, quantifies the largescale perturbation of the stratospheric composition and radiative balance, and describes the impact of satellite data assimilation. While the ref. ${ }^{28}$ reveals a number of remarkable similarities with respect to our approach and analysis, they report an average diabatic ascent rate of $8 \mathrm{~K} \mathrm{day}^{-1}$ whereas we find $5.9 \mathrm{~K} \mathrm{day}^{-1}$. An important point regarding the vortex dynamics and maintenance, which is not discussed in ref. ${ }^{28}$, is the need of a mechanism to suppress the negative potential vorticity produced by the isolated heating as discussed hereinbefore.

\section{Conclusions}

The observed and modelled planetary-scale repercussions of the Australian PyroCb outbreak around the turn of 2020 revolutionize the current understanding and recognition of the climatealtering potential of the wildfires. A single stratospheric overshoot of combustion products produced by the New Year's eve PyroCb event has led to an unprecedented hemispheric-scale perturbation of the stratospheric gaseous and aerosol composition, radiative balance and dynamical circulation with a prolonged effect. Whilst rivalling the volcanic eruptions in terms of stratospheric aerosol load perturbation, this exceptionally strong wildfire event had a substantial impact on a number of other climate-driving stratospheric variables such as water vapour, carbon monoxide and 
ozone. As the frequency and intensity of the Australian wildfires is expected to increase in the changing climate ${ }^{29}$, it is possible that this type of extraordinary event will occur again in the future eventually becoming a significant contributor to the global stratospheric composition.

This work reports the self-organization of an absorbing smoke cloud as a persistent coherent bubble coupled with a vortex that produces confinement preserving the compactness of the cloud. This structure is maintained and rises in the calm summer stratosphere due to its internal heating by solar absorption. The intensity, the duration and the extended vertical and horizontal path of this event certainly ranks it as extraordinary. More detailed studies will be necessary to understand fully the accompanying dynamical processes, in particular how a single sign vorticity structure emerges as a response to heating. Whether stratospheric smoke vortices have already occurred during previous large forest fires is to be explored.

\section{Methods \\ OMPS-LP. The Ozone Mapping and Profiler Suite Limb Profiler (OMPS-LP) on the Suomi National Polar-orbiting Partnership (Suomi-NPP) satellite, which has been in operation since April 2012, measures vertical images of limb scattered sunlight ${ }^{30}$. Aerosol extinction coefficient and ozone number density profiles are retrieved from the limb radiance using a two-dimensional tomographic inversion ${ }^{12}$ and a forward model that accounts for multiple scattering developed at the Uni- versity of Saskatchewan ${ }^{31}$. This OMPS-LP USask aerosol product is retrieved at $746 \mathrm{~nm}$ and has a vertical resolution of $1-2 \mathrm{~km}$ throughout the stratosphere. The aerosol extinction profiles are exploited to analyze the spatiotemporal evolution of the smoke plumes and for computing the mass of particulate matter lofted above the $380 \mathrm{~K}$ potential temperature level corresponding to $\sim 12-17 \mathrm{~km}$ altitude in the extratropics, see Fig. 2). The aerosol mass is derived from the aerosol extinction data assuming a particle mass extinction coefficient of $4.5 \mathrm{~m}^{2} \mathrm{~g}^{-1}\left(\right.$ ref. $\left.{ }^{2}\right)$.}

SAGE III. The Stratospheric Aerosol and Gas Experiment (SAGE) III provides stratospheric aerosol extinction coefficient profiles using solar occultation observations from the International Space Station (ISS) ${ }^{32}$. These measurements, available since February 2017, are provided for nine wavelength bands from 385 to $1550 \mathrm{~nm}$ and have a vertical resolution of approximately $0.7 \mathrm{~km}$. The SAGE III/ISS instrument and the data products have characteristics nearly identical to those from the SAGE III Meteor mission ${ }^{33}$. Here we use the $754 \mathrm{~nm}$ wavelength band for quantifying the error of OMPS-LP aerosol extinction retrieval (using 16-84 percentiles) and the wavelength pair 1019/521 nm for deriving the Angstrom exponent, which is used for the radiative forcing calculations.

CALIOP. The Cloud-Aerosol Lidar with Orthogonal Polarization (CALIOP) is a two-wavelength polarization lidar on board the CALIPSO mission ${ }^{10}$ that performs global profiling of aerosols and clouds in the troposphere and lower stratosphere. We use the total attenuated $532 \mathrm{~nm}$ backscatter level 1 product V3.40 which is available in near real time with a delay of a few days (doi:10.5067/CALIOP/ CALIPSO/CAL_LID_L1-VALSTAGE1-V3-40). The along track horizontal/vertical resolution are respectively $1 \mathrm{~km} / 60 \mathrm{~m}$ between 8.5 and $20.1 \mathrm{~km}, 1.667 \mathrm{~km} / 180 \mathrm{~m}$ between 20.1 and $30.1 \mathrm{~km}$, and $5 \mathrm{~km} / 300 \mathrm{~m}$ resolution between $30.1 \mathrm{~km}$ and 40 $\mathrm{km}$. The L1 product oversamples these layers with an actual uniform horizontal resolution of $333 \mathrm{~m}$.

MLS. The MLS (Microwave Limb Sounder) ${ }^{14}$ instrument on the NASA Aura satellite has been measuring the thermal microwave emission from Earth's atmospheric limb since July 2004 . With $\sim 15$ orbits per day, MLS provides day and night near-global $\left(82^{\circ} \mathrm{S}-82^{\circ} \mathrm{N}\right)$ measurement of vertical profiles of various atmospheric gaseous compounds (including $\mathrm{H}_{2} \mathrm{O}, \mathrm{CO}$ and $\mathrm{CH}_{3} \mathrm{CN}$ ) cloud ice, geopotential height, and temperature of the atmosphere. The measurements yield around to 3500 profiles per day for each species with a vertical resolution of $\sim 3-5 \mathrm{~km}$. For tracking the smoke bubble, we selected profiles bearing $\mathrm{CO}$ enhancements in the stratosphere exceeding $400 \mathrm{ppbv}$ and/or $\mathrm{H}_{2} \mathrm{O}$ enhancement exceeding $12 \mathrm{ppmv}$ with respect to the pre-event conditions (late December 2020). Stratospheric mass loads of $\mathrm{H}_{2} \mathrm{O}$, $\mathrm{CO}$ and $\mathrm{CH}_{3} \mathrm{CN}$ are derived from MLS volume mixing ratio measurements of species in log pressure space, molecular mass of the compound and the air number density derived from MLS temperature profile on pressure levels above the $380 \mathrm{~K}$ isentropic level and between $20^{\circ} \mathrm{S}$ and $82^{\circ} \mathrm{S}$. The error bars on the mass of injection are estimated by combining accuracies on the measurements and the mean standard deviations over 20-day periods before and after the sharp increase. The error bar on the $\mathrm{CH}_{3} \mathrm{CN}$ mass above $380 \mathrm{~K}$ is only calculated on the standard deviation because accuracies on $\mathrm{CH}_{3} \mathrm{CN}$ measurements are extremely large. The error bar on the aerosol mass takes also into account the uncertainty on the particle mass extinction coefficient $\left(1.5 \mathrm{~m}^{2} \mathrm{~g}^{-1}\right)$.
TROPOMI. The TROPOspheric Monitoring Instrument (TROPOMI) is a nadirviewing shortwave spectrometer jointly developed by the Netherlands Space Office and the European Space Agency on board the Sentinel 5 Precursor mission. The instrument has spectral bands in the ultraviolet $(270-500 \mathrm{~nm})$, the near-infrared $(710-770 \mathrm{~nm})$ and the shortwave infrared $(2314-2382 \mathrm{~nm})$ providing therefore observation of key atmospheric constituents, among which we use $\mathrm{O}_{3}$, CO and aerosol index at high spatial resolution $\left(7 \times 3.5 \mathrm{~km}^{2}\right.$ at nadir for the UV, visible and near-infrared bands, $7 \times 7 \mathrm{~km}^{2}$ at nadir for shortwave infrared bands) ${ }^{34}$. Here we exploit the Aerosol Index, and the $\mathrm{CO}$ and $\mathrm{O}_{3}$ columnar values from the offline Level 2 data. The aerosol absorbing index (AI) is a quantity based on the spectral contrast between a given pair of UV wavelength (in our case the $340-380 \mathrm{~nm}$ wavelengths couple). The retrieval is based on the ratio of the measured top of the atmosphere reflectance (for the shortest wavelength) and a pre-calculated theoretical reflectance for a Rayleigh scattering-only atmosphere (assumed equal for both wavelengths). When the residual value between the observed and modelled values is positive, it indicates the presence of UV-absorbing aerosols, like dust and smoke. Negative residual values may indicate the presence of non-absorbing aerosols, while values close to zero are found in the presence of clouds. AI is dependent upon aerosol layer characteristics such as the aerosol optical thickness, the aerosol single scattering albedo, the aerosol layer height and the underlying surface albedo. Providing a daily global coverage and a very high spatial resolution $\left(7 \times 3.5 \mathrm{~km}^{2}\right.$ at the nadir), the AI from TROPOMI is ideal to follow the evolution of smoke, dust, volcanic ash, or aerosol plumes.

Ozone. Copernicus Sentinel-5P (processed by ESA), 2018, TROPOMI Level 2 Ozone Total Column products. Version 01. European Space Agency. https://doi. org/10.5270/S5P-fqouvyz.

Carbon monoxide. Copernicus Sentinel-5P (processed by ESA), 2018, TROPOMILevel 2 Carbon Monoxide total column products. Version 01. European Space Agency. https://doi.org/10.5270/S5P-1hkp7rp.

Aerosol index. Copernicus Sentinel-5P (processed by ESA), 2018, TROPOMILevel 2 Ultraviolet Aerosol Index products. Version 01. European Space Agency. https:// doi.org/10.5270/S5P-0wafvaf.

GNSS-RO. We use Global Navigation Satellite System (GNSS) radio occultation (RO) dry temperature profiles acquired onboard Metop $\mathrm{A} / \mathrm{B} / \mathrm{C}$ satellites and processed in near real time mode at EUMETSAT RO Meteorology Satellite Application Facility (ROM SAF) ${ }^{35}$. For computing the composited temperature perturbation within the smoke bubble we use temperature profiles collocated with the vortex centroid as identified using IFS analyses $(8 \mathrm{~h}, 400 \mathrm{~km}$ collocation criteria). The perturbation is computed as the departure from a mean temperature profile within the corresponding spatiotemporal bin (3-day, $3^{\circ}$ latitude, $40^{\circ}$ longitude).

ECMWF IFS. ECMWF IFS is the operational configuration of the ECMWF global Numerical Weather Prediction system (46R1, https://www.ecmwf.int/en/ publications/ifs-documentation). It consists of an atmosphere-land-wave-ocean forecast model and an analysis system that provides an accurate estimate of the initial state. The forecast model has a $9 \mathrm{~km}$ horizontal resolution grid and 137 vertical levels, with a top around $80 \mathrm{~km}$ altitude. The analysis is based on a 4dimensional variational method, run twice daily using more than 25 million observations per cycle, primarily from satellites. The IFS produces high-resolution operational 10-day forecasts twice daily.

Radiative transfer calculations. The equinox-equivalent daily-average shortwave (integrated between 300 and $3000 \mathrm{~nm}$ ) surface and top of the atmosphere (TOA) direct radiative forcing $(\mathrm{RF})$ are estimated using the UVSPEC (UltraViolet SPECtrum) radiative transfer model in the libRadtran (library for Radiative transfer) implementation ${ }^{36}$ and a similar methodology as in ref. ${ }^{37}$ and ref. ${ }^{4}$ Baseline and fire-perturbed simulations are carried out with different aerosol layers: the average OMPS-LP aerosols extinction coefficient profiles, for January and February 2019 (baseline simulation) and January and February 2020 (fire-perturbed simulation). The spectral variability of the aerosol extinction is modeled using the measured Ångström exponent from SAGE III for January 2020 (fireperturbed simulation) and typical background values inferred from SAGE III (baseline simulation). Different hypotheses have been considered for the nonmeasured optical parameters of fire aerosols: single scattering albedo from 0.85 to 0.95 (typical of wildfire aerosols, see e.g., ref. ${ }^{38}$ ) and a Heyney-Greenstein phase function with an asymmetry parameter of 0.70 . More information about the UVSPEC runs can be found in the Supplementary Material. The daily-average shortwave TOA radiative forcing for the fire-perturbed aerosol layer is calculated as the SZA-averaged upward diffuse irradiance for a baseline simulation without the investigated aerosols minus that with aerosols, integrated over the whole shortwave spectral range. The shortwave surface radiative forcing is calculated as the SZAaverage downward global (direct plus diffuse) irradiance with aerosols minus the baseline, integrated over the whole spectral range. 
Mass estimation. The stratospheric masses of $\mathrm{CO}, \mathrm{CH}_{3} \mathrm{CN}$, and $\mathrm{H}_{2} \mathrm{O}$ are derived from the MLS species mixing ratios vertical profiles combined with MLS vertical profiles of pressure and temperature on the standard 37 pressure levels. MLS data are filtered according to the recommendations from the MLS team (https://mls.jpl. nasa.gov/data/v4-2_data_quality_document.pdf). $\mathrm{CH}_{3} \mathrm{CN}$ measurements are not recommended below $46 \mathrm{hPa}$ however have already been used successfully in a study on combustion products from Australian bushfires in the stratosphere ${ }^{39}$. The mass calculation is performed as follows. First, we calculate for each profile the partial column of species $\left(\mathrm{CO}, \mathrm{CH}_{3} \mathrm{CN}, \mathrm{H}_{2} \mathrm{O}\right)$ and air for each measurement layer (vertical resolution of $\sim 3 \mathrm{~km}$ ); the air partial column is derived from the difference in pressure between the top and bottom of the layer. Then, adding the partial columns in a profile, we derive the total column of species and air above the $380 \mathrm{~K}$ potential temperature $(\sim 12.17 \mathrm{~km}$ altitude), the so-called stratospheric "overworld"13. The ratio of the species and air total columns gives us the mean volume mixing ratios (VMR) of the species over the stratospheric profile. Finally, we calculate the mean VMR of all the profiles between $20^{\circ} \mathrm{S}$ and $82^{\circ} \mathrm{S}$ (which is the southernmost latitude of the MLS sampling) and multiply it by the molecular mass of the species and the total number of air molecules above $380 \mathrm{~K}$ and between $20^{\circ} \mathrm{S}$ and $82^{\circ} \mathrm{S}$ following ref. ${ }^{40}$ to obtain the total mass burden of the species plotted in Fig. 4. The aerosol mass is derived from the OMPS satellite aerosol extinction data assuming a particle mass extinction coefficient of $4.5 \mathrm{~m}^{2} \mathrm{~g}^{-1}$ following ref. ${ }^{2}$ Standard deviations of the injected mass are estimated by combining accuracies on the measurements and the mean standard deviations over 20-day periods before and after the sharp increase. The standard deviation of the $\mathrm{CH}_{3} \mathrm{CN}$ mass above 380 $\mathrm{K}$ is only calculated from the standard deviation because accuracies on $\mathrm{CH}_{3} \mathrm{CN}$ measurements are extremely large. The standard deviation of the aerosol mass takes also into account the uncertainty on the particle mass extinction coefficient $\left(\right.$ error $\left.=1.5 \mathrm{~m}^{2} \mathrm{~g}^{-1}\right)$

\section{Data availability}

MLS data are publicly available at http://disc.sci.gsfc.nasa.gov/Aura/data-holdings/MLS; GNSS-RO data at https://www.romsaf.org/product_archive.php; OMPS-LP data at ftp:// odin-osiris.usask.ca/ with login/password osirislevel2user/hugin; SAGE III data at https:// doi.org/10.5067/ISS/SAGEIII/SOLAR_BINARY_L2-V5.1; CALIOP data at https://doi. org/10.5067/CALIOP/CALIPSO/CAL_LID_L1-VALSTAGE1-V3-40; TROPOMI ozone data at https://doi.org/10.5270/S5P-fqouvyz; carbon monoxide data at https://doi.org/ 10.5270/S5P-1hkp7rp; Aerosol Index data at https://doi.org/10.5270/S5P-0wafvaf. The extracted ECMWF data used in this work are available at https://doi.org/10.5281/ zenodo.3958214.

\section{Code availability}

LibRadTran code exploited for radiative forcing calculations is available at http://www. libradtran.org/doku.php?id=download. The processing code for CALIOP, ECMWF data is available at https:/github.com/bernard-legras/STC-Australia with dependencies in https://github.com/bernard-legras/STC/tree/master/pylib. The processing code for TRIPOMI is available at https://github.com/silviabucci/TROPOMI-routines. The processing codes for MLS, OMPS-LP, SAGEIII, GNSS-RO are available at https://doi.org/ 10.5281/zenodo.3959259. The processing code for the estimation of injected masses using MLS data is available at https://doi.org/10.5281/zenodo.3959350.

Received: 16 June 2020; Accepted: 10 August 2020;

Published online: 21 September 2020

\section{References}

1. Khaykin, S. M. et al. Stratospheric Smoke with unprecedentedly high backscatter observed by lidars above Southern France. Geophys. Res. Lett. 45, 1639-1646 (2018).

2. Peterson, D. A. et al. Wildfire-driven thunderstorms cause a volcano-like stratospheric injection of smoke. Npj Clim. Atmospheric Sci. 1, 30 (2018).

3. Bourassa, A. E. et al. Satellite limb observations of unprecedented forest fire aerosol in the stratosphere. J. of Geophys. Res. Atmospheres 124, 9510-9519 (2019).

4. Kloss, C. et al. Transport of the 2017 Canadian wildfire plume to the tropics via the Asian monsoon circulation. Atmos. Chem. Phys. 19, 13547-13567 (2019).

5. Yu, P. et al. Black carbon lofts wildfire smoke high into the stratosphere to form a persistent plume. Science 365, 587-590 (2019).

6. Bauer, P., Thorpe, A. \& Brunet, G. The quiet revolution of numerical weather prediction. Nature 525, 47-55 (2015).

7. Boer, M. M., Resco de Dios, V. \& Bradstock, R. A. Unprecedented burn area of Australian mega forest fires. Nat. Clim. Chang. 10, 171-172 (2020).

8. Veefkind, J. P. et al. TROPOMI on the ESA sentinel-5 precursor: a GMES mission for global observations of the atmospheric composition for climate, air quality and ozone layer applications. Remote Sensing of Environment 120, 70-83 (2012).
9. NASA Earth Observatory Australian smoke plume sets records. https:// earthobservatory.nasa.gov/images/146235/australian-smoke-plume-setsrecords (2020)

10. Winker, D. M. et al. The CALIPSO mission: a global 3D view of aerosols and clouds. Bull. Am. Meteorol. Soc. 91, 1211-1230 (2010).

11. McCormick, M. P., Thomason, L. W. \& Trepte, C. R. Atmospheric effects of the Mt Pinatubo eruption. Nature 373, 399-404 (1995).

12. Zawada, D. J., Rieger, L. A., Bourassa, A. E. \& Degenstein, D. A. Tomographic retrievals of ozone with the OMPS Limb Profiler: algorithm description and preliminary results. Atmos. Meas. Tech. 11, 2375-2393 (2018).

13. Holton, J. R. et al. Stratosphere-troposphere exchange. Rev. Geophys. 33, 403-439 (1995).

14. Waters, J. W. et al. The earth observing system microwave limb sounder (EOS MLS) on the Aura satellite. IEEE Trans. Geosci. Remote Sens. 44, 1106-1121 (2006).

15. King, M. D., Platnick, S., Menzel, P., Ackerman, S. A. \& Hubanks, P. A. Spatial and temporal distribution of clouds observed by MODIS onboard the Terra and Aqua satellites. IEEE Trans. Geosci. and Remote Sens. 51, 3826-3852 (2013).

16. Haywood, J. M. et al. Observations of the eruption of the Sarychev volcano and simulations using the HadGEM2 climate model. J. Geophys. Res. 115, D21212 (2010).

17. Ridley, D. A. et al. Total volcanic stratospheric aerosol optical depths and implications for global climate change: Uncertainty in volcanic climate forcing. Geophys. Res. Lett. 41, $7763-7769$ (2014).

18. Schmidt, A. et al. Volcanic Radiative Forcing From 1979 to 2015. J. Geophys Res. Atmospheres 123, 12491-12508 (2018).

19. Brasseur, G. \& Solomon, S. Aeronomy of the Middle Atmosphere: Chemistry and Physics of the Stratosphere and Mesosphere, 3rd edn, 644 (Springer-Verlag, 2005).

20. Manney, G. L. et al. EOS Microwave Limb sounder observations of "frozen-in” anticyclonic air in Arctic summer. Geophys. Res. Lett. 33, L06810 (2006)

21. Allen, D. R. et al. Modeling the Frozen-In anticyclone in the 2005 arctic summer stratosphere. Atmos. Chem. Phys. 11, 4557-4576 (2011).

22. Thiéblemont, R., Orsolini, Y. J., Hauchecorne, A., Drouin, M.-A. \& Huret, N. A climatology of frozen-in anticyclones in the spring arctic stratosphere over the period 1960-2011. J. Geophys. Res. Atmos. 118, 1299-1311 (2013).

23. Hoskins, B. J., McIntyre, M. E. \& Robertson, A. W. On the use and significance of isentropic potential vorticity maps. Q. J. R. Meteorol. Soc. 111, 877-946 (1985).

24. Dritschel, D. G., Reinaud, J. N. \& McKiver, W. J. The quasi-geostrophic ellipsoidal vortex model. J. Fluid Mech. 505, 201-223 (2004).

25. Meunier et al. Intrathermocline eddies embedded within an anticyclonic vortex ring. Geophys. Res. Lett. 45, 7624-7633 (2018).

26. Stoffelen et al. The atmospheric dynamics mission for global wind field measurement. Bull. Am. Meteorol. Soc. 86, 73-88 (2005).

27. Rabier, F., Järvinen, H., Klinker, E., Mahfouf, J.-F. \& Simmons, A. The ECMWF operational implementation of four-dimensional variational assimilation. I: Experimental results with simplified physics. Q. J. R. Meteorol. Soc. 126, 1143-1170 (2000).

28. Kablick, G. P. III, Allen, D. R., Fromm, M. D. \& Nedoluha, G. E. Australian pyroCb smoke generates synoptic-scale stratospheric anticyclones. Geophysical Research Letters 47, e2020GL088101 (2020).

29. Dowdy, A. J. et al. Future changes in extreme weather and pyroconvection risk factors for Australian wildfires. Sci Rep. 9, 10073 (2019).

30. Flynn, L. E., Seftor, C. J., Larsen, J. C. \& Xu, P. in Earth Science Satellite Remote Sensing, 279-296 (Springer, Berlin, Heidelberg, 2006).

31. Bourassa, A. E., Degenstein, D. A. \& Llewellyn, E. J. SASKTRAN: a spherical geometry radiative transfer code for efficient estimation of limb scattered sunlight. J. Quant. Spectrosc. and Radiat. Transf. 109, 52-73 (2008).

32. Cisewski et al. The stratospheric aerosol and gas experiment (SAGE III) on the International Space Station (ISS) Mission. Proc. SPIE 9241, Sensors, Systems, and Next-Generation Satellites XVIII, 924107 (2014).

33. Thomason, L. W., Moore, J. R., Pitts, M. C., Zawodny, J. M. \& Chiou, E. W An evaluation of the SAGE III version 4 aerosol extinction coefficient and water vapor data products. Atmos. Chem. Phys. 10, 2159-2173 (2010)

34. Stein Zweers, D. C. TROPOMI ATBD of the UV aerosol index. S5P-KNMIL2-0008-RP, CI-7430-ATBD_UAVAI, V1.1, KNMI, Utrecht, The Netherland, http://www.tropomi.eu/sites/default/files/files/S5P-KNMI-L2-0008-RPTROPOMI_ATBD_UVAI-1.1.0-20180615 signed.pdf.

35. Gleisner, H., Lauritsen, K. B., Nielsen, J. K. \& Syndergaard, S. Evaluation of the 15 -year ROM SAF monthly mean GPS radio occultation climate data record. Atmos. Meas. Tech. 13, 3081-3098 (2020).

36. Emde, C. et al. The libRadtran software package for radiative transfer calculations (version 2.0.1). Geosci. Model Dev. 9, 1647-1672 (2016).

37. Sellitto, P. et al. Synergistic use of Lagrangian dispersion and radiative transfer modelling with satellite and surface remote sensing measurements for the 
investigation of volcanic plumes: the Mount Etna eruption of 25-27 October 2013. Atmos. Chem. Phys. 16, 6841-6861 (2016).

38. Ditas, J. et al. Strong impact of wildfires on the abundance and aging of black carbon in the lowermost stratosphere. Proc. Natl. Acad. Sci. USA 115, E11595-E11603 (2018).

39. Pumphrey, H. C., Santee, M. L., Livesey, N. J., Schwartz, M. J. \& Read, W. G. Microwave Limb sounder observations of biomass-burning products from the Australian bush fires of February 2009. Atmos. Chem. Phys. 11, 6285-6296 (2011).

40. Jacob, D. J. Introduction to Atmospheric Chemistry, 266, ISBN: 978-0-69100185-2 (Princeton University Press, Princeton, N.J.,1999)

41. Chouza, F. et al. Long-term (1999-2019) variability of stratospheric aerosol over Mauna Loa, Hawaii, as seen by two co-located lidars and satellite measurements. Atmos. Chem. Phys. 20, 6821-6839 (2020).

42. Guérette, E. E.-A. et al. Emissions of trace gases from Australian temperate forest fires: emission factors and dependence on modified combustion efficiency. Atmos. Chem. Phys. 18, 3717-3735 (2018).

\section{Acknowledgements}

CALIOP data were provided by the ICARE/AERIS data centre. The TROPOMI data were provided by the Copernicus Open Access Web https://scihub.copernicus.eu/. We thank the EUMETSAT's Radio Occultation Meteorology Satellite Application Facility (ROM SAF) for providing NRT temperature profile data. MLS data are provided by the NASA Goddard Space Flight Center Earth Sciences (GES) Data and Information Services Center (DISC). We thank the OMPS-LP team at NASA Goddard for producing and distributing high quality Level 1 radiances, and the SAGE III/ISS team at NASA Langley for data production and advice, in particular Dave Flittner. We acknowledge the support of ANR grant 17-CE01-0015. The providers of the libRadtran suite (http://www.libradtran.org/) are gratefully acknowledged. We acknowledge discussions with Guillaume Lapeyre, Riwal Plougonven and Aurélien Podglajen.

\section{Author contributions}

S.K. investigated the impact on the stratospheric gaseous composition, aerosol optical parameters and thermodynamical fields using OMPS-LP, MLS, GNSS-RO, SAGE III and Aeolus satellite observations. B.L. investigated the smoke bubble in the CALIOP data and diagnosed the vortex and its dynamics in the IFS analysis. S.B.u. analysed the TROPOMI data. P.S. calculated the radiative forcing. L.I. analysed the forcing of the vortex by the IFS assimilation. F.T., S.B.e. and J.J. have provided the estimates of injected mass of aerosols and gases using MLS and OMPS-LP data. A.B., L.R. and D.Z. provided OMPS-LP data and a detailed insight into limb-scatter data quality aspects. S.G.B. contributed to the results on aerosol perturbation in the stratosphere. S.K., B.L., S.B.u., P.S., L.I. and S.B.e. wrote the paper. All the authors contributed to the final version.

\section{Competing interests}

The authors declare no competing interests.

\section{Additional information}

Supplementary information is available for this paper at https://doi.org/10.1038/s43247020-00022-5.

Correspondence and requests for materials should be addressed to S.K.

Peer review information Primary handling editors: Heike Langenberg

Reprints and permission information is available at http://www.nature.com/reprints

Publisher's note Springer Nature remains neutral with regard to jurisdictional claims in published maps and institutional affiliations.

(c) (i) Open Access This article is licensed under a Creative Commons Attribution 4.0 International License, which permits use, sharing, adaptation, distribution and reproduction in any medium or format, as long as you give appropriate credit to the original author(s) and the source, provide a link to the Creative Commons license, and indicate if changes were made. The images or other third party material in this article are included in the article's Creative Commons license, unless indicated otherwise in a credit line to the material. If material is not included in the article's Creative Commons license and your intended use is not permitted by statutory regulation or exceeds the permitted use, you will need to obtain permission directly from the copyright holder. To view a copy of this license, visit http://creativecommons.org/ licenses/by/4.0/.

(C) The Author(s) 2020 